\title{
Research on the Cultivation of Humanistic Quality of Flying Cadets
}

\author{
Zhuoqi Li \\ Air Force Aviation University Flight Basic Training Base, Changchun, China \\ 294244476@qq.com
}

Keywords: Flying cadets; Humanities quality; Training

\begin{abstract}
Humanistic quality education plays a very important role in the all-round development of flying cadets. A flying cadet who is intelligent and lack of virtue may be more powerful, the greater the threat. This article from the concept of humanistic quality, analyzes the significance of humanistic quality training of flight cadets, and puts forward some measures for the cultivation of humanistic quality of students, and finally to my college students as an example, explained the practice of humanistic quality training of flight cadets, has a certain practical significance.
\end{abstract}

\section{Introduction}

With the transformation and development of the air force construction, it is urgent for the flying personnel to have a comprehensive and comprehensive ability, and the pilots should not only be the combatants to adapt to the future air combat, but also the future commanders. However, in recent years, according to the survey information on air force feedback, currently flying cadets in abilities there are problems of low ability and weak human connotation, occupation honor, coordination level is not high, the lack of awareness of innovation, communication and expression, the problem has restricted the development of flying cadets. In order to change the present situation, we must grasp the basic quality, optimize the knowledge structure, and promote the all-round development of the flying cadets. Humanistic quality is the quality of many people of the most fundamental and basic qualities, is the essential role of the quality of human development, has a strong penetration and influence on the formation and development of other people's quality. Therefore, in the military academy, training for pilots especially should attach great importance to the cultivation of students' humanistic quality, pay attention to the cultivation of students, the lofty spirit of patriotism, national spirit, indomitable will and sincere emotion with excellent traditional culture, in order to enhance the overall quality of students, cultivating talents for the modernization of the armed forces[1,2].

\section{The Concept of Humanistic Quality}

The humanistic quality is the comprehensive reflection of human's knowledge of literature, history, philosophy, morality, art and the spirit reflected by the knowledge system. Humanistic quality is the quality of many people of the most fundamental and basic qualities, is the essential role of the quality of human development, has a strong penetration and influence on the formation and development of other people's quality. The humanistic quality education is to make the excellent cultural achievements of human being be internalized into the personality, temperament and accomplishment of human being through the teaching of knowledge, the influence of environment and their own practice, so as to become the relatively stable inner quality of human being. The purpose of humanistic quality education is to guide students to learn to be human.

\section{The Significance of Cultivating the Humanistic Quality of Flight Cadets}

Humanistic Quality Education Is to Achieve People's All-Round Development Needs. With the rapid development of social economy and science and technology, education is beyond the limitations of traditional education, and gradually extended to its real field in time and space. In the new century, the demand for talents of social development is more diversified and personalized, which is a great challenge to the military academies and individuals. It is very important to do a 
good job of humanistic quality education at this stage, which is of great significance for the flying cadets to learn knowledge, learn to do, learn to live together and learn to be human.

Humanistic Quality Education Is an Important Support for the Long-Term Development Of Flight Personnel. Flying cadets are a special group, the quality of their humanistic quality is directly related to the quality of the future flight professional team. Not only to become a fighter to adapt to the future air combat fighters, but also to become the future of war commanders. Therefore, in order to adapt to the further study, students must have a comprehensive ability. The humanities is not only a kind of knowledge system, but also a kind of value system. Therefore, we should start from the basic quality, optimize their knowledge structure, to enhance the quality of humanities provides diversified training platform, which requires to lay a solid foundation for the growth of students, human progress and future work.

Humanistic Quality Education is the Objective Requirement of the Military Talents Personalized Training. At present, various social evils emerge in an endless stream, some students often lack the ability to identify the cause, their desires expansion, lead to shake the national self-confidence and national consciousness, value orientation scale tilt. Quality education emphasizes the continuous improvement of human beings, and pays attention to the personality development of the educated. Flying cadets as the future Army required flight personnel, also to the development needs of developing demand and military personal unity, determined to serve the country, serve the people, willing to contribute their talents for the air force flight career. To strengthen the education in this area, we must start from the basic education.

\section{Training Methods of Flying Cadets}

Through the Teaching to Teach the Knowledge of Humanities. Classroom teaching is the main channel to teach cultural and scientific knowledge to the students, teachers should according to "curriculum standards" requirements, mining favorable conditions the discipline of humanities education, develop specific objectives and requirements, there are plans to implement the humanistic quality education of students. In the teaching of humanities knowledge, we can cultivate students' correct outlook on life, world outlook and values. The history and philosophy of art and humanities courses since Needless to say, the mathematical and natural sciences also requires the teacher according to the teaching content of the students to seize the opportune moment of patriotism education, the implementation of scientific thinking method of education, innovative education, beauty education etc.. Teachers should strive to strengthen the discipline connotation of humanistic quality education and mutual penetration, knowledge, thought and interest together, especially to play an important role in Chinese teaching, highlighting the educational function, improve the quality of classroom instruction[3].

Rich Campus Cultural Activities. Campus culture is a kind of mass activity, which takes students as the main body, campus as the main space, and campus spirit as its main characteristics. The rich cultural activities play an irreplaceable role in the understanding of the society, broaden their horizons, cultivate the sense of responsibility and enhance the sense of mission. Through the campus culture and Art Festival, sports festival, student literary associations and interest groups, seminars, competitions and other activities, to respect students' interests and hobbies, give full play to their potential and strengths, weaknesses, let the students grow together each one takes what he needs. Through extra-curricular reading activities to increase the students' humanistic knowledge, cultural heritage, teachers should make plans for students to study, read a book, to strengthen the guidance.

To strengthen the campus cultural environment construction. The quality education of students depends on their own efforts and the influence of the environment. Strong cultural atmosphere is a good school spirit, style of study, teaching the external manifestations of the wind, the character of the students to cultivate, enhance the realm, the sublimation of emotion plays a subtle role. Therefore, communication and cultural knowledge in the use of classroom teaching to carry out extracurricular activities of the humanistic spirit of the experience and practice, attention should also be paid to students' campus cultural environment of self education and self selection. 
The human environment can be subtle to carry out the "people" and "plastic heart" education, from class to class, from the campus life to the point of view of the college environment, all affect the formation of students' Humanistic quality. Therefore, we should think deeply about environmental education, overall planning, strengthen the construction of cultural environment, interpersonal environment and so on, so that it has a strong cultural atmosphere[4].

To Improve the Humanistic Quality of Teachers, Administrators. Teachers should teach students cadres and grass-roots management of the greatest impact on the students, stay together morning and night, the two teams will make an example for the students, with their own words and deeds and actions for the students to set up the life and values of the model, determine the direction of life with their own personal experience and first-hand experience to help students, behavior, influence thinking, habits and hobbies of students strong. So the two teams to establish the first awareness of the truth and the power of personality influence and Inspiration of students, practice teaching, education management responsibilities; to strengthen their self-cultivation, teachers, grass-roots management cadres to conscientiously study the education theory, management theory, psychological theory, extensive reading books of Humanities and Social Sciences; to actively participate in all kinds of practice activities, a sound body and mind, the perfect personality for the students to do the demonstration.

\section{Study on the Cultivation of Students' Humanistic Quality}

Teaching Models, Outstanding Humanities Education Purpose. At present, some teaching is still in accordance with the "passing through" teaching methods, although it helps students grasp the characteristics and the development of a subject, but from the perspective of humanistic education, various disciplines, a staggered unrelated topic, lack of concentration is distinct, connotation is not conducive to highlight the humanistic quality education. Therefore, we need to update the teaching model, highlighting the theme of humanistic education. For example, in the course of College Chinese, we can classify the works of the textbooks, break the boundaries of genre, and classify them according to different subjects. At the same time, these works were classified in the thematic section of the concentration of teaching. The change of this teaching mode, from the perspective of the form only from the genre as a guide to lead to changes in the theme, but in essence, it is the course of College Chinese teaching focus from focusing on its knowledge and tools, to focus on the humanistic quality education of College Chinese curriculum, completely change the past works about work the teaching materials of teaching materials, the status quo, and focus in the training, pay attention to students' personality, edify sentiment will temper, spirit of innovation development in a broader context, will play its role in multiple aspects of fostering students' comprehensive quality[5].

The Reform of Teaching Methods, Stimulate Students' Enterprising Spirit. First, carefully designed scenarios to guide students to explore the spirit of noble quality. In the teaching of flexible use of "situational teaching" method, the students of the humanities spirit of education and guidance. "The implementation of situational teaching method" is divided into two steps: the first step is the teacher according to different contents, combining life experience, design scenarios, require students to provide teachers according to the description or video information of the scene, imagine yourself in the special background of the author, such as in combat, danger, injustice, displaced, destiny, of vital importance and so on, think of the situation, feelings, thoughts, experiences, strong endurance, active, open-minded, proud, and noble qualities, so as to enrich their emotion cognition, enhance their ability to create a good emotional experience, their mental quality. The second step is to ask the students in an oral or written form, through personal statements or classroom discussion summary of the way to sort out the feeling, harvest experience. This part is mainly to let students discuss and express, but according to the specific circumstances of the classroom teacher to guide and inspire, and further deepen their understanding of the problem, so that they understand the lofty spirit of the great personality, stimulate their inner strong sense of justice and make contributions to the man of pride.

The two is to grasp the upper reaches of the students to seek the psychological, with the results 
of incentive law to motivate students to actively, to show talent, improve capacity. "Achievement motivation" is a kind of motivation theory, which is based on the expectation theory and cognitive evaluation theory in psychology. According to this theory, the more one is I believe as long as their efforts to improve learning performance, and can improve the performance for and obtain the corresponding reward, and that this award is very valuable, so his motive force will be more intense. The application of the theory and method in the writing part and the practical teaching process, students first specify the learning objectives and tasks, and incentive evaluation according to performance and achievement, stimulate students' strong desire of identity. For example, excellent classroom performance is outstanding, academic progress to give timely praise and affirmation, especially through active participation in various activities to obtain different levels of reward, stimulate students' positive psychological, strengthen their academic pursuit of beauty and beautiful realm of etc..

Combined with the Office Needs, Strengthen Students' Mind the World, the Ambition Accomplishment in Teaching Contents. The work of frontier fortress is an important teaching content of College Chinese, and it is also the key theme of human education. My school students have a part from the vast vast northwest of the theater, including many place in history was the ancient battlefield, the wind howling maming the glint and flash of cold steel, such as Qinghai, Kroraina, Luntai, Tianshan, common names go horse Sichuan, Yumen Pass, Yang poem some equilateral plug, still in use, some the remaining sites, in our Qinghai, Xinjiang, the northwest region in Gansu area. Ancient soldiers in the northwest border desolate, lonely, cold and hard environment long-term border operations, even if the "sand battle" and "golden armour worn", even "energy-saving" still maintained high fighting enthusiasm; even seeing the mid war bones buried outside the sigh of "shortage" of the ancient battle no one is still back "with" thousands of miles at the dead, once the firm belief of success "--. Read this poem, feel the truth, as soldiers will be moved, will be encouraged, inspired, and thus the association as a result of our contemporary military mission and responsibility. This part works as the narrative description, or lyrical chanting, either praise praise or expose ridicule, everywhere between the lines there is a strong patriotic sentiment, the heart of the country and patriotic ambition, is an excellent material for us to carry out patriotic education.

In previous teaching, the contents of the works of the frontier fortress are scattered in every part of the teaching materials, which are not concentrated, not systematic, the theme is not prominent, and the teaching content is not full. In the course of teaching reform, we can combine the characteristics of the environment and the actual operation of the war zone to make the project more systematic and scientific.

Organize Teaching Activities, Training Students to Stimulate the Consciousness of Innovation Quality. According to the progress of teaching and the teaching content of the stage, or with the mission of the college, the author has launched various forms of humanistic quality education practice activities. From a variety of aspects to expand the students' knowledge and humanistic vision, cultivate their patriotic dedication, strengthen their will quality, enhance their humanistic quality. Practice can set the following contents (1) classic poetry readings (each teaching 1); (2) the theme of the speech contest (each semester $1 \sim 2$ times); (3) debate (1 each semester); (4) essay competition (at any time outside the military related information actively organize students to participate in); (5) frontier culture education.

Flexible Use of a Variety of Evaluation Methods, a Comprehensive Assessment of the Comprehensive Quality of Students. In the evaluation mode, to diversify the direction of development, focus on the examination "ability not test", such as the cooperation ability, creative ability, ability, organization ability, expression ability and social activity ability, these "test not" ability is the most important goal of flying cadets education. At the same time, the multiplicity of teaching content and the diversity of teaching methods also require the reform and exploration of the contents, methods and means of assessment according to the characteristics of the course.

The examination takes the schoolwork as the form, takes the achievement as the standard, pays great attention to the process appraisal. "Achievement" includes two aspects: professional ability 
and general ability. The achievement of professional ability refers to the ability of students to master, apply and innovate their professional knowledge when they finish their lessons and other tasks. In order to ensure the accuracy of the assessment, teachers should be given a clear level of evaluation for each lesson and every class activities. And the requirements of the standard content is very clear, with a strong practicality. Results general refers to the ability of students in the classroom learning and complete academic activities such as process, ability of showing the self-management, communication and cooperation with people, solve problems and complete tasks, operation and application of modern science and technology, design and innovation. No matter what kind of results, are students in the completion of the task of learning in the process of gradual accumulation, are the basis for teachers to assess the performance of students.

The examination is based on schoolwork, and is used in many forms. According to the characteristics of the examination subjects, adopt diversified evaluation methods, such as closed book, open book examination; examination and oral combination; oral, written test and operation skills of the combination, or take the paper, design, production, Research Report of writing and defense combined; also can be used without standard answer questions, thinking method, emphatically their ideas, opinions and assessment methods. Work with the traditional sense of different operation, the training is aimed at completing teaching objectives at the same time, training and exercise of general ability, so that students can exercise in practice, and through the academic understanding of their own in the two aspects of professional skills and general ability and potential areas of development, in order to promote their self-improvement needs work is the embodiment of students; how to learn, teachers give students independent learning opportunities, real topic, Zhenti really do.

Scientific evaluation of students' academic achievement. The end of the course examination and process assessment of the achievements of the students, as an important basis for judging the results of trainees. For different courses, the scoring method can take different forms, such as using percentile, can also take five points, namely excellent, good, pass, fail to reach; course, can be used in two grades, namely compliance with non-compliance or passing and failing of thesis design; and making teaching, can use the evaluation plus five grades, to confirm their academic achievement. Due to the diversity of the contents, methods and methods of the examination, the school shall formulate measures for strengthening the examination of the teaching examination and the relevant rules for the implementation thereof, so as to ensure the orderly conduct of the teaching work.

To establish and perfect the relevant management system of humanistic quality curriculum evaluation and assessment, and to improve the credit system management. The reform of examination method is directly related to the control of the learning process. In the process of learning, the effective management system can not only serve as the basis of the management process, but also enhance the pressure and motivation of the students. The establishment of the system of curriculum examination quality analysis, the content of the examination, the proposition and the results of the examination should be carefully analyzed, and constantly improve the examination and evaluation methods. We will improve the credit system management approach, scientifically plan the credit structure, and provide the minimum credits for the humanities quality courses in compulsory, limited and optional credits. The establishment of the comprehensive quality evaluation system for students, and to a certain degree of credit to assess the overall quality of students to be fixed to the training plan, all students must achieve the teaching objectives.

\section{Conclusion}

Humanistic quality education plays a very important role in the all-round development of flying cadets. This article from the concept of humanistic quality, analyzes the significance of humanistic quality training of flight cadets, and puts forward some measures for the cultivation of humanistic quality of students, and finally to my college students as an example, analyzes the research and practice of cultivating humanistic quality of flying cadets, has a certain practical significance. 


\section{References}

[1] Y.Y. Huang. Research on the quality education of University [J]. Journal of Naval Aeronautical Engineering Institute (Comprehensive Edition), 2006.2. (In Chinese)

[2] M. Jiang, Y.Z. Mou. On the quality education of flying cadets [M]. Jilin: Jilin people's publishing house, 2012. (In Chinese)

[3] Y.J. Xu. An analysis of the effective operation of the incentive mechanism of the staff learning [J].New vocational education, 2000.11:31. (In Chinese)

[4] Z.Q. Li. Quartet played the most humane quality of flying cadets [J].language teaching communication, 2011,7-8. (In Chinese)

[5] Y. Zhao. Humanistic quality education [M].Jilin: Jilin people's publishing house, 2003. (In Chinese) 